\title{
A esfera pública e as lutas por reconhecimento: De Habermas a Honneth*
}

\author{
Olivier Voirol*
}

\section{RESUMO:}

O PRESENTE ARTIGO PRETENDE EXAMINAR OS PRINCÍPIOS QUE SE ENCONTRAM NO FUNDAMENTO DA ANÁLISE DA ESFERA PÚBLICA, ANALISAR SEUS ELEMENTOS E DISCUTIR SEUS ALCANCES. DOIS ÂMBITOS DO PROJETO NORMATIVO SERÃO CONSIDERADOS: A DEFINIC̄̃O DA AUTONOMIA DO SUJEITO E A ANÁLISE DOS MECANISMOS DESTRUIDORES DA ESFERA PÚblicA. SERÄO APRESENTADOS, AINDA, CERTOS ASPECTOS E RESULTADOS DO PROJETO DE HABERMAS, QUE PROCURA TRADUZIR SOCIOLÓGICA E HISTORICAMENTE OS PRINCÍPIOS DA FILOSOFIA KANTIANA, VINCULANDO-OS AO DIAGNÓSTICO DA TEORIA CRÍTICA DA "ESCOLA DE FRANKFURT".

PALAVRAS-CHAVE: HABERMAS, HONNETH, ESFERA PÚBLICA, RECONHECIMENTO

\section{ABSTRACT:}

THIS PAPER AIMS AT EXAMINING THE PRINCIPLES THAT GROUND THE ANALYSIS OF THE PUBLIC SPHERE, ANALYSING ITS ELEMENTS AND DISCUSSING ITS LIMITS. TWO AREAS OF THE NORMATIVE PROJECT WILL BE TREATED: THE DEFINITION OF THE AUTONOMY OF THE SUBJECT AND THE ANALYSIS OF THE MECHANISMS THAT DESTRUCT THE PUBLIC SPHERE. CERTAIN ASPECTS AND RESULTS OF HABERMAS' PROJECT OF TRANSLATING BOTH SOCIOLOGICALLY AND HISTORICALLY THE PRINCIPLES OF KANTIAN PHILOSOPHY BINDING THEM TO THE DIAGNOSIS OF THE CRITICAL THEORY OF THE "FRANKFURT SCHOOL" WILL ALSO BE PRESENTED.

KEYWORDS: HABERMAS, HONNETH, PUBLIC SPHERE, RECOGNITION

O conceito de esfera pública vem ganhando uma importância cada vez maior no campo das ciências sociais e humanas no decorrer dos últimos dez anos, como testemunham as obras publicadas e o número de pesquisas que se orientaram por essa questão. A abordagem sobre a esfera pública encontra sua origem, em grande medida, na obra de Habermas publicada em alemão, em 1962, sob o título de Strukturwandel der Öffentlichkeit, que mobiliza um quadro de análise articulado sobre o princípio de publicidade e ancorado nos princípios normativos da filosofia kantiana. A esfera pública é, com efeito, um conceito normativo que não representa somente os acontecimentos em curso nas sociedades democráticas contemporâneas, mas incorpora os ideais ancorados nas práticas políticas e nas concepções éticas. ${ }^{1}$ No

"Título original: "L'espace public et les luttes pour reconnaissance: De Habermas à Honneth". In: Barril, C.; Carrel, M.; Guerrero, J-C.; Márquez, A. (orgs.). Le public en action: Usages et limites de la notion d'espace public en sciences sociales. Paris: L'Hartmattan, 2003.

"Professor na Universidade de Lausanne.

${ }^{1}$ Cf. Quéré, L. "Agir dans l'espace publique". In: Pharo, P., Quere, L (orgs.). Les formes de l'action. Paris: Ed. De l'EHESS ("Raisons pratiques”), p. 42. 
presente texto, vamos nos debruçar sobre os princípios que se encontram no fundamento da análise da esfera pública, examinar seus elementos e avaliar seus limites. Duas dimensões, reveladoras do projeto normativo, serão precisamente consideradas: a definição da autonomia do sujeito e a análise dos mecanismos destruidores da esfera pública. Tratar-se-á de apresentar certos aspectos e resultados do projeto de Habermas, o qual se esforça por traduzir sociológica e historicamente os princípios da filosofia kantiana, relacionando-os ao diagnóstico da teoria crítica da "Escola de Frankfurt". Resulta de seu empreendimento uma teoria complexa da esfera pública, sob a forma da teoria da ação e da formalização das condições universais de possibilidade da comunicação social (a pragmática universal). Entre os críticos dessa abordagem, um lugar particular será dado aqui a Axel Honneth, que toma distância diante da teoria habermasiana em relação a dois pontos essenciais: a teoria da linguagem e a questão dos conflitos sociais. Honneth propõe uma correção, pelo viés de uma teoria das lutas por reconhecimento, que permite enriquecer a pesquisa sociológica sobre a esfera pública.

\section{As origens da teoria da esfera pública.}

Enquanto Habermas trabalhava em sua obra Strukturwandel der Offentlichkeit no final dos anos cinqüenta, ele tinha em mente o livro Dialética do esclarecimento, obra redigida por Adorno e Horkheimer durante seu exílio americano. ${ }^{2}$ Marcada pela experiência histórica do nazismo, pelo surgimento da cultura de massa nos Estados Unidos e pela política stalinista na União Soviética, a constatação de Horkheimer e Adorno é inapelável: a razão se transformou em instrumento de dominação; a cultura não visa mais a razão, o Aufklärung, mas a manipulação das massas com a finalidade de propaganda política e publicitária; o capitalismo liberal deu lugar ao capitalismo monopolista e o Estado liberal burguês do século XIX, ao Estado autoritário. Podemos dizer em suma

${ }^{2}$ Horkheimer, M.; Adorno, T. W. La dialetique de la raison. Paris: Gallimard, 1974. 
que, segundo Adorno e Horheimer, a esfera pública está completamente desintegrada e nenhum dos ideais "iluministas" sobreviveram no "mundo administrado". Não há lugar nesse diagnóstico para a formação autônoma de uma opinião pública, e isso sobretudo porque os indivíduos, nas sociedades modernas dominadas pela razão instrumental, perderam aquilo que os caracterizava como indivíduos, a saber, sua capacidade para formar de maneira autônoma juízos racionais. Eles não passam de "frágeis indivíduos" submetidos sem resistência às diferentes instâncias de poder: a indústria cultural e os partidos fascistas em voga.

O jovem Habermas será fortemente influenciado por esse diagnóstico da "Escola de Frankfurt". ${ }^{3}$ Mas o pessimismo de Adorno e Horkheimer em relação ao destino histórico da razão lhe parece certamente excessivo e, sobretudo, incapaz de indicar as orientações normativas apropriadas para defender o projeto emancipatório da modernidade. Habermas, então, tentará reencontrar, na própria história, os elementos de um projeto que possa responder ao ideal da razão emancipatória. Ele os encontrou nas estruturas de sociabilidade e de comunicação da burguesia culta do final do século XVIII. Desse modo, as práticas das pessoas privadas reunidas em um público e que se entretinham com obras da cultura oferecem a base de um modelo de comunicação sem coerção entre pessoas livres no uso público da razão. O princípio kantiano de publicidade se situa no centro dessa concepção. Ela pode ser sintetizada em três dimensões principais e supõe: em primeiro lugar, que as pessoas privadas façam um uso público de sua razão, o que significa

\footnotetext{
${ }^{3}$ A questão de saber se a elaboração teórica de Habermas ainda permanece ancorada na herança da "Teoria crítica" da Escola de Frankfurt ou se, ao contrário, decorre desta de maneira decisiva, foi objeto de interpretações divergentes. Para alguns, ela implica uma ruptura com o projeto da "Teoria crítica" - englobando principalmente o trabalho do grupo de intelectuais reunidos em torno do Institut für Sozialforschung dos anos trinta até os setenta (cf. principalmente Bouchindomme, C. "Introdution à l'édition française". In: Habermas, J. Morale et communication. Paris: Cerf, 1986, pp. 7-17). Para outros, ela contribuiu para tirar essa tradição teórica de suas aporias ao oferecer um projeto emancipatório pelo viés de uma atitude tanto filosófica - ao visar seus próprios fundamentos normativos - como sociológica, pela sua articulação com os saberes positivos das ciências sociais (cf. principalmente Honneth, A. "Von Adorno zu Habermas. Zum Gestaltwandel kritischer Gesellschaftstheorie". In: Bonß, W.; Honneth, A. (orgs.) Sozialforschung als Kritik. Frankfurt: Suhrkamp, pp. 87-126; Honneth, A. "La dynamique sociale du mépris. D'où parle une théorie critique de la société". In: Bouchindhomme, C.; Rochlitz, R. (orgs.) Habermas, la raison, la critique. Paris: Cerf, 1996, pp. 215-38).
} 
tornar públicas a uma audiência as razões privadas - pensar por si mesmo significa, de qualquer modo, pensar tout haut; em segundo lugar, que as pessoas privadas sejam autônomas, ou seja, segundo Kant, capazes de constituir uma linha de conduta correspondente aos imperativos morais universais, capacidade em que o exercício verdadeiro é exclusivo de pessoas livres (o que significa "estar em posse de uma propriedade", pois somente os proprietários são senhores de si mesmos); em terceiro lugar, que o poder legislativo esteja submetido ao juízo de um público que faz um uso público de sua razão e seja, por conseguinte, fruto de um consenso público.

O princípio de publicidade é um ideal normativo, uma ficção política separada dos fatos. Mas, sendo assim, possui um potencial de orientação da ação. O projeto de Habermas consiste em se apoiar sobre esse princípio para construir seu próprio quadro de análise da esfera pública. Assim, a análise das mutações estruturais da esfera pública se encontra marcada por esse empreendimento de tradução sociológica de uma categoria filosófica e visa uma análise detalhada de sua transformação histórica. Desse modo, Habermas mostra que na época do Esclarecimento as três dimensões próprias do princípio kantiano de publicidade se concretizaram nas estruturas sociais historicamente identificáveis. Primeiramente, nos espaços de sociabilidade burguesa, em que pessoas privadas se reuniam em um público fazendo um uso público de sua razão, se constitui uma opinião pública que é o produto de um processo de deliberação orientada pelo princípio do melhor argumento e pela busca comum de consenso. Em segundo lugar, as pessoas privadas constituindo essa esfera pública se beneficiam de uma autonomia individual fundada na estrutura da família burguesa, nos seus modos de socialização e em sua relação com a propriedade privada. Em terceiro lugar, as decisões do poder político são submetidas à deliberação crítica e não decorrem das instâncias "sagradas" do poder, tais como a religião ou a instituição real, o que supõe uma crítica da política do segredo e a realização do princípio da soberania democrática.

Apoiando-se sobre o princípio de publicidade e mostrando em que este último pode ser traduzido na história como um princípio normativo de orientação prática no centro de esferas sociais específi- 
cas, Habemas é capaz de identificar uma esfera de emancipação na história, lá onde Adorno e Horkheimer tinham visto a dominação crescente da racionalidade instrumental. Mas neste ponto Habermas não está tão longe de seus mestres, pois retoma suas teses fundamentais, esforçando-se na tentativa de historicizá-las. Nesse sentido, não é de espantar que encontremos, em Mudança estrutural da esfera pública, os motivos principais desenvolvidos por Adorno e Horkheimer: declínio do capitalismo liberal em face do capitalismo monopolista, desestruturação da família burguesa, progressão do mundo administrado, racionalização estatal, etc. A fase de declínio da esfera pública, marcada pela transformação da publicidade crítica em publicidade manipuladora, pela criação da mercantilização da cultura, pela perda de autonomia individual e pelo declínio do indivíduo são os temas centrais do diagnóstico dos membros da Escola de Frankfurt em relação à evolução das sociedades modernas. O princípio da dominação da racionalidade instrumental aparece como o peso negativo presente na origem do declínio da esfera pública, ainda que o princípio kantiano de publicidade apareça, desde as primeiras pesquisas de Habermas, como núcleo normativo no fundamento de sua teoria. A contribuição decisiva de Habermas consiste em ter tentado historicizar e sociologizar o princípio de publicidade e as teses da Dialética do esclarecimento, em torná-los férteis para os historiadores e sociólogos e oferecer uma análise crítica fundada filosoficamente sobre os princípios normativos assumidos como tais.

\section{A reformulação da teoria da esfera pública na pragmática universal}

A partir de então, a obra de Habermas ganhou em complexidade, ainda que o edifício teórico continue repousando sobre os fundamentos kantianos utilizados. Assim, no prefácio à reedição de Mudança estrutural da esfera pública, Habermas sublinha:

Depois desse período de elaboração, nos anos cinqüenta e no início dos anos sessenta, as pesquisas e as questões teóricas evidentemente se modificaram... Finalmente minha própria teo- 
ria se modificou, claro que menos nos seus traços principais do

que em seu grau de complexidade. ${ }^{4}$

Os desenvolvimentos seguintes podem ser vistos como uma reformulação da teoria da esfera pública. A reformulação de seu projeto fundador faz apelo certamente a um aparato conceitual novo. Em primeiro lugar, Habermas opera uma diferenciação entre interação e trabaIho, entre uma ação prático-moral e comunicacional e uma ação instrumental de matriz técnica sobre o mundo. ${ }^{5}$ Uma tal diferenciação da ação será desenvolvida de maneira mais complexa na Teoria da ação comunicativa com as noções de sistema e mundo da vida. A racionalidade instrumental, que acompanha a dominação técnica sobre o mundo, não aparece mais desde então como a única forma de racionalidade: uma racionalidade está em curso nos atos de comunicação da vida cotidiana. ${ }^{6}$ Uma tal diferenciação comporta uma dupla vantagem. De um lado, ela autoriza Habermas a ver a obra da razão emancipatória nos atos comunicativos cotidianos - o que não era possível na versão anterior da Teoria crítica, segundo a qual a racionalidade instrumental, caracterizada pelo empreendimento do capitalismo e da administração técnica, passava por cima do universo dos atos comunicativos - e, de outro lado, ela permite identificar na atividade prática em curso uma esfera comunicativa que responde ao princípio kantiano de publicidade. ${ }^{7}$

Semelhantemente a Kant, preocupado em atualizar as condições de expressão pública dos juízos, Habermas se esforça em identificar as condições práticas e universais do entendimento comunicativo. Isso será chamado por ele de pragmática universal, a qual parte do seguinte

\footnotetext{
${ }^{4}$ Habermas, J. "L'espace public trente ans après". In:

L'espace public. Arqueologie de la publicité come dimension constitutive de la société bourgeosie. Paris: Payot, 1993, p. II.

${ }^{5}$ Cf. Habermas, J. La technique et la science comme "ideologie". Paris: Gallimard, 1973.

${ }^{6}$ Cf. Habermas, J. Théorie de l'agir communicationnel. Paris: Fayard, 1987.

${ }^{7}$ Notamos que Habermas abandona a "crítica imanente" que consistia em fundar os princípios da crítica na realidade histórica (cf. Mudança estrutural da esfera pública) em detrimento da "crítica transcendente" (cf. a Ética do discurso) que consiste em fundar os princípios da crítica nos pressupostos universais e incontornáveis da atividade comunicativa. Habermas se apóia agora sobre as condições práticas do entendimento comunicativo no centro das esferas do discurso. Um tal deslocamento foi notado por certas críticas formuladas por Honneth em relação à sua teoria.
} 
questionamento: como é possível que o uso da linguagem leve à compreensão mútua? "Pragmática" porque Habermas se debruça sobre as regras em uso, sobre os modos de utilização da linguagem na comunicação corrente, a saber, a linguagem tal como ela ocorre, tal como se realiza e age no mundo. Essa pragmática pretende ser "universal" porque seus sistemas de regras estruturam inevitavelmente toda a situação da comunicação. Habermas defende assim o projeto de uma pragmática formal universal, e isso significa que ele é capaz de transcender de forma apropriada as culturas e as épocas. Ele enuncia seu projeto nos seguintes termos:

É tarefa da pragmática universal reparar e reconstruir as condições de possibilidade universais do entendimento mútuo. Em outros contextos, fala-se também de "pressuposições universais da comunicação"; de minha parte, prefiro falar das pressuposições universais da atividade comunicativa, pois tomo por fundamental o tipo de atividade que busca o entendimento mútuo. ${ }^{8}$

Nesse projeto de reconstrução das condições gerais de êxito dos atos lingüísticos, Habermas coloca em evidência as modalidades de validade das práticas comunicativas, reagrupadas sob quatro universos pragmáticos situados no pano de fundo de todo ato da linguagem (a inteligibilidade, a verdade, a sinceridade e a conformidade à situação). Habermas supõe, sobretudo, que por meio da linguagem um consenso universal pode ser alcançado sem o exercício da coerção, de tal modo que a linguagem pressupõe inevitavelmente $o$ consenso e uma ordem coletiva ideal.

Em sua reformulação da segunda dimensão do princípio de publicidade, sobre a questão da autonomia individual, Habermas renunciou completamente ao modelo psicanalítico próprio das pesquisas dos membros da primeira geração da Escola de Frankfurt e que ainda estava fortemente presente em seus primeiros trabalhos sobre a esfera pública. $\mathrm{O}$ acesso à autonomia não está mais ligado às condições econô-

\footnotetext{
${ }^{8}$ Habermas, J. Logique des sciences sociales et autres essais. Paris: P.U.F., 1987, p. 392.
} 
micas ou às disposições subjetivas adquiridas no decorrer do processo de socialização no seio da família burguesa. A autonomia não remete mais ao foro interior, às competências puramente subjetivas ou monológicas, mas a um processo dialógico em que as normas e as interpretações são submetidas à deliberação. Ela remete à capacidade de reflexão das pessoas sobre suas próprias preferências, suas perspectivas de ação, sobre o peso de suas conseqüências do ponto de vista daquelas e daqueles que são afetados. A autonomia surge, em outros termos, da aquisição das competências comunicativas: uma pessoa é autônoma desde que disponha das competências comunicativas necessárias para participar em um processo de deliberação racional, desde que seja capaz de tomar parte em uma argumentação reflexiva e pública apoiada sobre uma avaliação dos enunciados normativos com base em um ponto de vista moral dialógico e supostamente descentrado. ${ }^{9}$

Enfim, em relação à terceira dimensão do projeto kantiano, aquela do consenso público, as modificações realizadas implicam renunciar ao conceito de totalidade que caracterizava a primeira teoria da esfera pública em proveito de uma conceitualização da complexidade social inspirada pela teoria dos sistemas. Em Mudança estrutural da esfera pública, a análise da transformação estrutural da esfera pública foi marcada pelo princípio da auto-organização da sociedade: a administração de toda a sociedade por ela mesma por meio da submissão do conjunto de seus domínios de atividade - compreendendo aquele da reprodução econômica - à legislação que emana da vontade coletiva. Em seus trabalhos posteriores, Habermas relativiza seu modelo de uma sociedade que age sobre si mesma em proveito de uma teoria da diferenciação funcional do mundo social orientado por uma concepção da complexidade sistêmica. ${ }^{10} \mathrm{O}$ sistema econômico regulado pelo mercado, de um lado, e o sistema administrativo regulado pelo poder, de outro lado, segundo Habermas, não podem ser afetados em sua totalidade pelo processo de formação democrática da vontade sem que a eficácia da reprodução social seja colocada em perigo. Em Direito e democracia, Habermas introduz o conceito de poder comunicativo, que

${ }^{9}$ Cf. Mahoney, J. "Honneth's ethical theory of recognition". In: International Studies in Philosophy, 31 (1), pp. 99-110.

${ }^{10} \mathrm{Cf}$. Habermas, J. Théorie de l'agir communicationnel. 
reformula a idéia kantiana de um poder legislativo submetido ao processo de validação da coletividade. ${ }^{11}$ A mediação entre sociedade e Estado, que no livro Mudança estrutural da esfera pública repousava sobre o uso da razão de pessoas privadas reunidas em um público, é assim retraduzida nos termos de um processo de institucionalização dos processos comunicativos do mundo da vida nas estruturas jurídicas do Estado democrático de direito. Segundo essa concepção, o funcionamento do sistema administrativo se beneficia de uma grande autonomia em relação aos processos civis de comunicação, mas ele deve poder ser submetido a qualquer momento às redefinições propostas pela cooperação comunicativa que se manifesta no cerne da sociedade civil.

Na sua reformulação da teoria da esfera pública, Habermas renovou igualmente a análise dos mecanismos destruidores das dinâmicas de constituição de espaços de deliberação. Ele não mais analisa esses processos em termos de um declínio histórico progressivo, mas em termos de tendências que surgem no presente. Os imperativos funcionais da economia e os processos de imposição do poder - que, aos olhos de Habermas, aparecem como inevitáveis considerando-se a diferenciação estrutural das sociedade modernas - ameaçam o universo do entendimento comunicativo através da extensão de sua esfera de influência. ${ }^{12}$ Eles causam sistematicamente um curto-circuito nas esferas de ação estruturadas pelo entendimento lingüístico, enfraquecendo progressivamente as formas de coordenação baseadas na linguagem e sua capacidade de estruturar o mundo da vida social. Um tal processo de extensão das esferas de ação instrumental estreita $o$ acordo obtido pela linguagem e ameaça assim sufocar os processos públicos de formação democrática da vontade. É isso que Habermas chama de "colonização do mundo da vida".

\section{Críticas em relação a Habermas}

A construção teórica de Habermas suscitou numerosas discus-

\footnotetext{
${ }^{11}$ Cf. Habermas, J. Droit et démocratie. Entre faits et normes. Paris: Gallimard, 1996.

${ }^{12} \mathrm{Cf}$. Habermas, J. Théorie de l'agir communicationnel.
} 
sões e foi objeto de múltiplas objeções, advindas tanto da filosofia como das ciências sociais e das disciplinas históricas. ${ }^{13}$ Sem pretender dar conta da totalidade dessas críticas, é possível destacar algumas tendências argumentativas gerais. Desse modo, podemos reunir uma primeira série de críticas que se inserem na dimensão factual da análise. Os trabalhos dos historiadores colocam em evidência o fato de que as análises de Habermas tendem a supervalorizar o grau de efetividade do princípio de publicidade na época do Esclarecimento. ${ }^{14}$ Habermas respondeu a seus críticos em seu novo prefácio à reedição de Strukturwandel der Öffentlichkeit, reconhecendo a pertinência dessas objeções e a necessidade de uma reformulação da análise tendo por referência os saberes históricos desenvolvidos posteriormente. ${ }^{15}$ Outros trabalhos, principalmente em sociologia e ciência política, procuram operacionalizar empiricamente o conceito de esfera pública. Eles privilegiam uma abordagem centrada nos repertórios desse discurso público, nos regimes de justificação e nas constrições discursivas a que se submetem os atores para ascender à inteligibilidade pública. A visibilidade pública necessita de procedimentos moldados à forma da comunicação, supondo o domínio dos recursos argumentativos que possam mobilizar uma multiplicidade de operações de categorização e tipificação. Esse tipo de abordagem da esfera pública se concentra na emergência de formas inéditas de debate social e atribui uma maior importância aos registros das expressões habitualmente desconsideradas como discurso político, tais como o registro da emoção e dos afetos ou aquele das experiências vividas. Uma tal perspectiva, ao dar atenção à pluralidade dos espaços de argumentação, supõe uma modificação na acepção empírica da noção de esfera pública e uma ruptura com uma concepção homogênea e unificada dessa noção. ${ }^{16}$

\footnotetext{
${ }^{13}$ Cf. Honneth, A.; Jonas, H. (orgs.) Communicative action. Essays on Jürgen Habermas's The theory of communicative action. Cambridge: Polity Press, 1991; Calhoun, C. (org.). Habermas and the public sphere. Cambridge: MIT Press, 1992.

${ }^{14}$ Calhoun, C. (org.) Habermas and the public sphere; Bernan, R.; Hohendal, P. U.; Kenkel, K.; Strum, A. Öffentlichkeit. Geschichte eines kritischen Begriffs. Stuttgart: J. B. Metzler, 2000.

${ }^{15}$ Habermas, J. "L'espace public trente ans après".

${ }^{16}$ François, B.; Neveu, E. (orgs.) Espaces publiques mosaiques: acteurs, arènes et rhétoriques dês débats publics contemporains. Rennes: Presse universitaires de Rennes, 1999.
} 
A esse tipo de reformulação crítica é preciso sem dúvida acrescentar aquelas críticas que questionam a idealização do modelo habermasiano da esfera pública e seus pressupostos, ou seja, a possibilidade igual para todas e todos de participar de uma deliberação coletiva. A observação mais elementar de uma situação de comunicação coloca em evidência a desigual participação em uma deliberação, o desequilíbrio na expressão dos pontos de vista, os processos de imposição das opiniões, a recusa do acesso à esfera de discussão, a dominação lingüística ou ainda a posse desigual dos recursos simbólicos indispensáveis para a argumentação pública. Tais constatações invalidariam, segundo os críticos, o modelo de esfera pública. Habermas responde a esses argumentos dizendo que o princípio de publicidade seria uma ficção política e que, mesmo se restam dúvidas quanto à sua realização efetiva, o princípio orienta as práticas sociais e inspira as reivindicações políticas e, desse modo, moldou e continua a moldar a instituição da esfera pública.

Uma segunda categoria de críticas se concentra mais diretamente no próprio modelo de esfera pública em Habermas e procura discutir os elementos relativos à base normativa sobre a qual aquele se apóia. Três tipos de argumentos podem ser desenvolvidos nesse caso. Primeiro, a teoria da esfera pública não permite pensar a diversidade das formas de vida social. A idéia da razão comunicativa e da pragmática universal tende a excluir toda pessoa ou todo grupo social que não se conforma a essa razão e despreza as regras institucionais da argumentação pública. Os participantes do diálogo devem pressupor um sistema moral implícito do discurso. Se sua definição não é universalmente compartilhada, muito menos o são aquelas competências que ele requer. Ao fundar sua teoria sobre uma tal concepção de comunicação, Habermas não chega a conceber a multiplicidade social da esfera pública - os públicos dentro do público - e corre o risco de ratificar, na teoria, a exclusão efetiva de grupos sociais ou de categorias sociais dominadas, como as mulheres, a classe trabalhadora ou as minorias culturais. A exclusão das mulheres e aquela da classe trabalhadora aparecem, em certas críticas, como constitutiva da esfera pública burguesa, a qual exerce, por conseguinte, um papel repressivo. ${ }^{17} \mathrm{Em}$ se-

\footnotetext{
${ }^{17}$ Cf. Fraser, N. "Rethinking the public sphere: a contribution to the critique of actual
} 
gundo lugar, a teoria habermasiana da esfera pública, fundada em um ideal de comunicação sem dominação nem relações de poder, nos obriga a pressupor a capacidade dos atores sociais de colocar os conflitos entre parênteses na prática discursiva. O processo público de argumentação só pode ser concebido como já emancipado em face da dominação e como uma realização prática do consenso pela linguagem. ${ }^{18} \mathrm{Em}$ terceiro lugar, na concepção habermasiana da interação social, os atores sociais são concebidos como se, antes de qualquer coisa, fossem portadores de pretensões de validade, ou seja, como atores abstratos e desencarnados e não como pessoas dotadas de um corpo e permanentemente formando sua identidade. A concepção exclusivamente lingüística de esfera pública favorece o esquecimento da corporeidade e da experiência social, principalmente aquela demandada pela emergência dos contra-públicos - que dão lugar a experiências inéditas de real autoorganização política e escapam ao princípio de valorização mercantil. ${ }^{19}$

As três criticas da teoria habermasiana aqui consideradas levam sem dúvida a uma reformulação profunda do modelo de esfera pública. Os trabalhos realizados por Axel Honneth sintetizam de maneira convincente essas três críticas, retrabalhando-as no cerne de uma concepção articulada sobre o conceito de reconhecimento. A crítica formulada por Honneth apresenta um interesse particular, pois conduz a uma concepção modificada de esfera pública, embora permaneça inscrita no quadro teórico desenvolvido por Habermas.

\section{A teoria das lutas por reconhecimento}

Como aluno de Habermas, Axel Honneth discutiu amplamente sua obra e, em certos aspectos, passou-a no pente-fino da crítica. Con-

existing democracy". In: Calhoun, C. (org.) Habermas and the public sphere; Negt, O.; Kluge, A. Öffentlichkeit und Erfahrung. Zur Organisationsanalyse von bürgelicher und proletariatischer Öffentlichkeit. Frankfurt: Suhramp, 1972.

${ }^{18}$ Cf. Dean, J. "Civil society: beyond the public sphere". In: Rasmussen, D. M. (org.) Handbook of critical theory. Oxford: Blackwell Publishers, 1996, pp. 220-4.

${ }^{19} \mathrm{Cf}$. Negt, O.; Kluge, A. Öffentlichkeit und Erfahrung. Zur Organisationsanalyse von bürgelicher und proletariatischer Öffentlichkeit. 
trariamente a Habermas, que inscreve sua concepção de esfera pública no modelo kantiano, Honneth se inspira essencialmente em Hegel e na sua concepção de reconhecimento. ${ }^{20}$ Três distanciamentos serão considerados aqui: a crítica, inicialmente, de um mundo da vida sem relações de poder; a introdução, por conseguinte, de um modelo de luta social na teoria da esfera pública; e, por fim, a crítica do modo de análise das ameaças que pesam sobre a esfera pública contemporânea - as tendências "patológicas" das sociedades capitalistas contemporâneas.

A pragmática universa/ parece problemática aos olhos de Honneth, que formula muitas objeções. Inicialmente, ela parece abstrata e considera muito pouco a experiência moral por que passam os atores sociais no momento de sua participação na dinâmica pública. Em um processo de deliberação, os atores sociais não levantam somente de maneira discursiva pretensões de validade, mas formulam expectativas de reconhecimento. ${ }^{21} \mathrm{O}$ participante espera não apenas que seus enunciados encontrem lugar no processo de argumentação, mas também que toda sua pessoa seja considerada de maneira positiva. Em outros termos, 0 acesso a uma dinâmica pública de argumentação supõe, além do domínio das regras de interação e das competências comunicativas concomitantes, uma relação positiva do sujeito consigo mesmo e com o outro, sem a qual as bases elementares para garantir a plena participação na esfera pública não são asseguradas. A relação consigo mesmo é uma construção social que toma forma nas relações do sujeito com um outro: é na ação do outro em relação a si mesmo que o sujeito toma consciência de seu próprio valor e faz a experiência do reconhecimento - mas se confronta também potencialmente com sua própria vulnerabilidade e com a experiência da negação do reconhecimento e do desrespeito social..$^{22} \mathrm{~A}$ relação intersubjetiva tematizada no quadro de uma teoria do reconhecimento supõe uma definição alargada da

${ }^{20} \mathrm{Cf}$. Honneth, A. Kampf um Anerkennung. Zur moralischen Gramatyk sozialer Konflikte. Frankfurt: Suhrkamp, 1992.

${ }^{21} \mathrm{Cf}$. Honneth, A. "La dynamique sociale du mépris. D’où parle une théorie critique de la société".

${ }^{22}$ Cf. Renault, E. Mépris social. Éthique et politique de la reconnaisannce. Bègles: Ed. Du Passant, 2000. 
interação que não se funda somente sobre uma teoria da linguagem, mas integra elementos como a corporeidade e as pretensões morais de reconhecimento adquiridas no decorrer do processo de socialização. Honneth amplia assim o quadro de análise habermasiana, centrado nos procedimentos e nas competências comunicativas, para as condições intersubjetivas do reconhecimento, constitutivas da aquisição e da atualização das competências lingüísticas. $O$ processo de socialização que torna possível a relação positiva do sujeito consigo mesmo excede a interação lingüística e supõe uma teoria da comunicação integrando as dimensões extra-linguísticas e as expectativas morais. Conseqüentemente, as condições comunicativas do entendimento sem coerção evidenciadas pela pragmática universal não esgotam o conjunto de condições da interação social, uma vez que as expectativas normativas que os sujeitos associam ao engajamento nas relações de comunicação estão ligadas às pretensões de reconhecimento social.

A autonomia do sujeito não poderá, portanto, ser assegurada simplesmente pela aquisição de competências comunicativas e pela capacidade de participar em uma argumentação reflexiva e pública. Ela se constitui, segundo Honneth, por um senso de integridade que o sujeito possui em relação a si próprio, que se co-constrói nas relações comunicativas lingüísticas e extra-linguísticas e que supõe, por sua vez, o reconhecimento por parte do outro e uma capacidade de afirmar sua própria especificidade. Honneth retoma assim, a seu modo, a abordagem da constituição do "si" segundo um processo de ajustamento às disposições do outro desenvolvido por George Herbert Mead. ${ }^{23} \mathrm{O}$ processo de formação da individualidade é visto por este como produto de uma tensão entre uma experiência consciente do me e o surgimento inconsciente do eu. $\mathrm{O}$ eu remete à parte incontrolada que se exprime de maneira impulsiva sem uma atividade reflexiva do sujeito; ele precede o horizonte de consciência que o sujeito tem de si mesmo e de seus parceiros de interação e se revela como um reservatório de impulsos de onde emerge uma ação criativa não submetida à objetivação. Ao contrário, o me remete à constituição consciente do sujeito e à sua capacidade de se

${ }^{23}$ Cf. Mead, G. L'esprit, le soi et la société. Paris: PUF, 1963. 
tomar por objeto graças à sua faculdade de se colocar no lugar do outro. O me, que se constitui assim na interação e na linguagem, corresponde à imagem formada a partir da perspectiva dos interlocutores e traduz 0 fato de que o indivíduo chega à consciência de si na medida em que adota a perspectiva do outro. Para Honneth, uma tal distinção permite, por sua vez, dar conta da singularidade dos sujeitos sociais e do caráter intersubjetivo do processo de individuação. A singularidade do sujeito depende, portanto, das estruturas intersubjetivas e das relações de reconhecimento, pois permite assegurar que encontremos no outro e na coletividade, nos diferentes níveis da estrutura do reconhecimento, o respeito social constitutivo de uma relação positiva do sujeito consigo próprio. A concepção de autonomia do sujeito, constitutiva da dinâmica da esfera pública, se encontra portanto modificada em relação àquela de Habermas: passamos de uma concepção centrada na competência comunicativa para uma concepção centrada na integridade de si.

O exercício do desrespeito social que implica, por exemplo, a violência psíquica, a exclusão da coletividade política, a humilhação pública, tem implicações negativas sobre a construção de si, mas também causa graves problemas para a autonomia dos sujeitos e sua capacidade de participar na dinâmica da esfera pública. Segundo Honneth, a pragmática universal não permite integrar essa experiência do desrespeito e fracassa ao tentar dar conta da riqueza de experiências sociais da vida cotidiana. ${ }^{24}$ Ela peca, por conseguinte, pelo seu caráter abstrato. Seu foco sobre a linguagem a impede de captar as experiências ou as lutas sociais não formuladas segundo princípios morais articulados na linguagem. Ela também não chega a dar conta da dinâmica das lutas sociais, pois seus motivos não repousam em ofensas às regras implícitas do entendimento comunicativo, mas na ofensa às pretensões de reconhecimento e às convicções morais. As motivações das lutas sociais e formas de resistências políticas não respondem aos critérios lingüísticos formulados pela concepção de esfera pública teorizada por Habermas, tendendo assim a lhe escapar. De acordo com Honneth, "o potencial de

\footnotetext{
${ }^{24} \mathrm{Cf}$. Honneth, A. "La dynamique sociale du mépris. D’où parle une théorie critique de
} la société". 
ação moral por parte das classes sociais dominadas não pode entrar no campo de visão da ética do discurso porque suas principais categorias estão muito centradas na dimensão linguisticamente articulada dos princípios morais". 25

Honneth toma o exemplo dos grupos sociais dominados e das formas de conflito que não se manifestam imediatamente nas sociedades atuais. Ele parte do princípio de que existem formas múltiplas de morais, diferenciadas e socialmente situadas, mas que a expressão pública dos sentimentos de injustiça se encontra abafada por sutis formas de repressão simbólica. A formulação dos princípios morais supõe a mobilização dos recursos simbólicos e o apelo a uma instância de abstração moral que é socialmente distribuída. ${ }^{26}$ Por exemplo, os grupos sociais que participam do poder político e econômico são levados, devido à sua posição social, a justificar a ordem social da qual retiram seus privilégios. Seus membros desenvolvem assim um sistema de valores estruturado e articulado na linguagem. O acesso à formação escolar Ihes assegura o domínio sobre os recursos simbólicos permitindo a decodificação de suas próprias normas de ação e sua inscrição no cerne de um sistema de valores suplantando as situações específicas de ação. Por outro lado, os grupos sociais dominados escapam da necessidade de elaborar de maneira estruturada e de justificar as convicções morais referentes à generalidade da ordem social, fazendo com que sua posição social não os incite nem a uma reelaboração reflexiva nem a uma generalização lógica dos conteúdos implícitos de sua prática. As reivindicações morais dos grupos dominados tendem a ficar à margem das formulações públicas de injustiça. Seus membros se consideram perfeitamente aptos a tratar os problemas morais de seu entorno imediato de maneira normativamente segura e eticamente refletida. Uma moralidade implícita está operando e deve ser apreendida como uma forma de expressão de injustiça social não articulada em uma linguagem sistemática. ${ }^{27}$ Uma

\footnotetext{
${ }^{25}$ Honneth, A. The fragmented world of the social. Essays in social and political philosophy. Albany: State University of New York Press, 1995, p. xiv.

${ }^{26}$ Cf. Honneth, A. "Moralbewußtsein und soziale Klassenherschaft. Einige Schwierigkeiten in der Analyse normativer Handlungspotentiale". In: Die zerrissene Welt des Sozialen. Frankfurt: Suhrkamp, 1990, pp. 182-201.

${ }^{27}$ Cf. Honneth, A. Das Andere der Gerechtigkeit. Aufsätze zur praktischen Philosophie. Frankfurt: Suhrkamp, 2000.
} 
teoria da esfera pública que não chega a considerar as experiências não organizadas linguisticamente em um sistema de convicções morais explícitas passa ao largo das formas de conflitos não imediatamente visíveis na sociedade atual.

Diante dos limites da pragmática universal, Honneth propõe um quadro teórico que permite a análise empírica das motivações morais das lutas sociais. ${ }^{28} \mathrm{O}$ paradigma da comunicação concebido não mais nos termos de uma teoria da linguagem, mas de uma teoria do reconhecimento, permite a passagem de uma teoria do consenso a uma teoria do conflito social. ${ }^{29} \mathrm{~A}$ teoria da esfera pública de Habermas está orientada pelo consenso: os participantes da comunicação enunciam argumentos racionais dirigidos à busca de um acordo. Honneth vê essa pressuposição do consenso como redutora e critica Habermas, no curso dos anos setenta, por ter tomado o caminho de uma teoria do consenso e da racionalização. Ele crê que o modelo de interação retirado de Hegel, que Habermas defendia nos anos sessenta, Ihe abriria um caminho que permitiria desenvolver uma teoria do conflito, da ação coletiva e das lutas sociais no seio da esfera pública:

Ao desenvolver a idéia de processo de aprendizagem evolutivo de sistemas de ação sociais, nos quais o processo de racionalização deveria ocorrer de maneira intersubjetiva, ele [Habermas] suspende a alternativa teórica [do primeiro modelo da comunicação social] que, em seu segundo modelo de sociedade baseado sobre uma teoria da comunicação, teria um custo muito alto. Em vez de passar imediatamente ao conceito de sistema social, Habermas poderia ter tirado proveito da idéia de ação coletiva para evitar a representação equivocada de um sujeito da espécie uniforme. Os processos sociais de aprendizagem, por meio dos quais as sociedades se desenvolvem, não se caracterizariam por

\footnotetext{
${ }^{28}$ Cf. Honneth, A. Kampf um Anerkennung.

${ }^{29}$ Cf. Iser, M. Kommunikation oder Anerkennung als Paradigma Kritischer Theorie? Über Differenzen der Gesellschaftskritik bei Jürgen Habermas und Axel Honneth. Diplomarbeit, Freie Universität Berlin; Cusset, Y. "Lutte sociale et éthique de la discussion". In: Actuel Marx, 25, pp. 123-35.
} 
um macro-sujeito nem por sistemas de ação anônimos, mas por experiências específicas de grupos sociais trabalhadas de maneira comunicativa e que levam historicamente às novas convicções e concepções. Uma tal perspectiva teórica permitiria interpretar o processo de racionalização como um processo no qual os grupos sociais lutam para dar forma às instituições sociais e [as desenvolver]. Ao mesmo tempo, atribuiríamos um papel prático decisivo no processo de reprodução das sociedades às orientações das ações e aos valores sociais ligados aos grupos sociais. ${ }^{30}$

Portanto, é à retomada desse programa, deixado prematuramente em aberto por Habermas, que Honneth encontra-se comprometido, ou seja, ao desenvolvimento de uma concepção de lutas sociais não ancoradas em uma definição estratégica da ação e das motivações do conflito. ${ }^{31}$ Ao propor uma teoria não instrumental do conflito, que escapa do modelo da teoria da escolha racional, ele evita reduzir a questão da luta ao agir estratégico, tal como aconteceria com Habermas. A teoria do conflito desenvolvida por Honneth se insere no cerne de sua discussão sobre esfera pública. A dinâmica da esfera pública aparece como resultado das lutas sociais causadas por motivos normativos e por reivindicações de reconhecimento. As lutas sociais se desenvolvem na medida em que os indivíduos ou grupos sociais se sentem lesados nas suas expectativas de reconhecimento. A estrutura da atividade comunicativa se funda sobre uma infra-estrutura normativa constituída por tais expectativas de reconhecimento. A experiência do desrespeito significa a decepção em relação a essas expectativas e desperta sentimentos morais tais como a cólera, a revolta, a indignação, o sentimento de injustiça, a desonra, etc. A ameaça que recai sobre a relação do sujeito consigo mesmo e a experiência da desvalorização resultante do desrespeito social levam os atores sociais à luta social, tematizada sob a forma da luta por reconhecimento.

\footnotetext{
${ }^{30}$ Honneth, A. "Habermas' Theorie der Gesellschaft: Eine kommunikationstheoretische Transformation der Dialektik der Aufklärung”. In:___. Kritik der Macht. Reflexionstufen einer kritischen Gesellschafstheorie. Frankfurt: Suhrkamp, 1986, pp. 313-4.

${ }^{31} \mathrm{Cf}$. Honneth, A. Kampf um Anerkennung.
} 
Honneth não recorre a um quadro de análise que mobiliza uma definição intrumental da ação e desenvolve uma concepção própria de mecanismos de decomposição da esfera pública. Não há um domínio universal da razão instrumental como em Adorno e Horkheimer, nem uma "colonização do mundo da vida" como em Habermas. Formulada em termos de "colonização do mundo da vida", a análise das ameaças que recaem sobre a esfera pública contemporânea parece levar a um caminho equivocado na medida em que se utiliza de duas esferas de interação social desprovidas de mediação e reguladas de maneira interna pelos processos específicos e exclusivos - um mundo da vida desprovido das relações de poder e um sistema caracterizado unicamente pela dominação. ${ }^{32}$ Um tal distanciamento em relação a Habermas leva Honneth a uma outra análise das formas de declínio da esfera pública contemporânea e nos convida a pensar sobre a infra-estrutura do reconhecimento na sociedade contemporânea:

É necessário que o ponto de vista do diagnóstico histórico seja modificado em relação à abordagem habermasiana. Não são mais as tensões entre sistema e mundo da vida que devem ser colocadas no centro, mas as causas sociais responsáveis pela violação sistemática das condições de reconhecimento. ${ }^{33}$

As potencialidades de uma deliberação pública são ameaçadas quando as condições de uma relação positiva dos sujeitos em referencia a si próprios, e, portanto, seu acesso à autonomia, não são mais preenchidas. A expectativa de reconhecimento não preenchida supõe uma perturbação do processo intersubjetivo da construção de si e faz com que os atores, ao se verem como vítimas da negação do reconhecimento no processo intersubjetivo de socialização, se revelem pouco dispostos à autonomia do juízo e à afirmação de uma dinâmica pública de argumentação. ${ }^{34}$

\footnotetext{
${ }^{32}$ Cf. Honneth, A. Kritik der Macht. Reflexionstufen einer kritischen Gesellschafstheorie. ${ }^{33}$ Honneth, A. "La dynamique sociale du mépris. D'où parle une théorie critique de la société", p. 230.

${ }^{34}$ Cf. Honneth, A. Leiden an Unbestimmtheit. Stuttgart: Reclam, 2001.
} 
Conclusão: paradigma do reconhecimento e análise sociológica da esfera pública

As modificações operadas pela teoria do reconhecimento no cerne do paradigma da comunicação da Teoria Crítica têm como vantagem possibilitar os acessos simbólicos e normativos que garantem a plena participação na argumentação pública e que, de um ponto de vista normativo, asseguram a validade da teoria habermasiana da esfera pública, apresentando assim um interesse para a pesquisa em ciências sociais sobre a esfera pública.

Vimos que a perspectiva do reconhecimento busca completar uma concepção de esfera pública centrada na formulação de enunciados ou de pretensões de validade apoiando-se, assim, nas pretensões de reconhecimento, e realizando as experiências da relação do sujeito consigo mesmo e com o outro. A estrutura normativa da comunicação social não se resume somente àquelas modalidades únicas da troca de argumentos, mas engloba as modalidades de auto-realização por meio de atos discursivos e não discursivos. A interação social não é regulada somente pelo acordo, mas também pelo reconhecimento da singularidade e do valor da ação dos sujeitos individuados. Essa concepção ampliada de interação comunicativa abre uma primeira série de pesquisas que se apóiam não somente sobre as dimensões argumentativas da interação social, mas também sobre as dimensões informais, extra-linguísticas e corporais, bem como sobre as condições de uma relação positiva do sujeito consigo mesmo, constitutiva da plena participação na argumentação pública. Não se trata de forma alguma de recuar diante das abordagens da intersubjetividade prática ${ }^{35}$ ao reintroduzir uma dimensão psicológica, mas antes de considerar a base normativa da comunicação social em seu conjunto. O processo de individuação e a relação positiva a si mesmo se constitui intersubjetivamente: o valor de si e sua própria ação na base de uma relação positiva do sujeito consigo mesmo é algo

\footnotetext{
${ }^{35}$ Cf. Quéré, L. "Agir dans l'espace public"; Habermas, J. "La raison communicationnelle: une outre voi pour sortir de la philosophie du sujet". In: de la modernité. Paris: Galimard, 1988, pp. 348-96. . Le discours philosophique
} 
inseparável das validações do outro e dos juízos dos participantes na interação, seja real ou ideal. A pesquisa sociológica pode então se apoiar sobre os modos de validade das pretensões de reconhecimento, bem como sobre os modos de exercício do desrespeito social. Ela se interessa pela esfera pública como um lugar de confrontação não somente entre enunciados, mas entre as convicções morais e políticas defendidas pelos indivíduos ou grupos sociais e que se encontram ancoradas nas formas de vida. Ela supõe uma concepção de comunicação social capaz de dar conta da multiplicidade, das diferenciações e dos tipos de conflitos entre os gêneros, os grupos sociais ou entre as classes sociais. Por outro lado, ela dá atenção aos aspectos negligenciados por uma abordagem exclusivamente centrada nas formas lingüísticas de expressão pública para se concentrar nas condições sociais e simbólicas da participação na esfera pública, sobre os modos de invisibilidade social e as orientações morais informais.

Uma segunda série de possibilidades diz respeito aos conflitos sociais. Enquanto o conflito aparece como algo "reprimido" na teoria habermasiana da esfera pública, o conflito em torno de demandas de reconhecimento, satisfeitas ou não, aparece como a base constitutiva da dinâmica da argumentação pública. A reprodução simbólica do mundo social opera assim através das interações cooperativas e conflituosas entre indivíduos ou grupos sociais procurando alcançar a distribuição social do reconhecimento. As situações conflituosas revelam a estrutura normativa implícita nas interações comunicativas e a ordem instituída de reconhecimento, ou seja, os aspectos que operam às costas das mediações intersubjetivas reguladas normativamente. É na ruptura com a evidência factual das formas estabelecidas da distribuição de reconhecimento que as condições do entendimento comunicativo consensual podem ser reconstruídas sobre uma base normativa explícita e, portanto, renovadas: a explicação das normas que estruturam a ordem de reconhecimento torna possível sua redefinição pelo viés da argumentação pública. ${ }^{36}$ Uma tal perspectiva estimula, nos parece, uma pesquisa preocupada com a "gramática dos conflitos sociais" (Honneth), com os pro-

\footnotetext{
${ }^{36}$ Cf. Hunyadi, M. La vertu du conflit. Paris: Cerf, 1995.
} 
cedimentos e as condições de formulação das demandas que mobilizam o conflito público. Ela amplia a visão de investigação sociológica sobre o pano de fundo da moral, por meio da qual os atores chegam a "ver como" identificar suas experiências como derivando da negação do reconhecimento. Essa análise sociológica suplanta assim aquelas análises de procedimentos públicos operadas para tornar inteligíveis os acontecimentos e ocorrências e organizá-los sob uma forma narrativa, apoiando-se assim sobre a infra-estrutura normativa dessas relações e das expectativas formuladas pelos atores durante suas lutas. Ela procura saber qual forma de cultura moral confere aos indivíduos ou grupos vítimas do desrespeito social a força de articular suas experiências e suas reivindicações em um espaço público democrático, bem como nas formas de expressão que excluem a argumentação pública. Em outros termos, a análise dos procedimentos que se voltam para a inteligibilidade da ação é acompanhada de uma análise da estrutura normativa constitutiva da relação positiva do sujeito consigo mesmo ou dos grupos aptos a alcançar a inteligibilidade da ação e do mundo social, e a cumprir expectativas legítimas de reconhecimento.

Tradução de Rúrion Soares Melo 


\section{BIBLIOGRAFIA:}

BARRIL, C.; CARREL, M.; GUERRERO, J-C.; MÁRQUEZ, A. (orgs.) Le public en action: Usages et limites de la notion d'espace public en sciences sociales. Paris: L'Hartmattan, 2003.

BERNAN, R.; HOHENDAL, P. U.; KENKEL, K.; STRUM, A. Öffentlichkeit. Geschichte eines kritischen Begriffs. Stuttgart: J. B. Metzler, 2000.

BOUCHINDOMME, C. "Introdution à l'édition française". In: HABERMAS, J. Morale et communication. Paris: Cerf, 1986.

CALHOUN, C. (org.). Habermas and the public sphere. Cambridge: MIT Press, 1992.

CUSSET, Y. "Lutte sociale et éthique de la discussion". In: Actuel Marx, 25.

DEAN, J. "Civil society: beyond the public sphere". In: RASMUSSEN, D. M. (org.) Handbook of critical theory. Oxford: Blackwell Publishers, 1996.

FRANÇOIS, B.; NEVEU, E. (orgs.) Espaces publiques mosaiques: acteurs, arènes et rhétoriques dês débats publics contemporains. Rennes: Presse Universitaires de Rennes, 1999

HABERMAS, J. La technique et la science comme "ideologie". Paris: Gallimard, 1973. . Logique des sciences sociales et autres essais. Paris: PUF, 1987.

Théorie de l'agir communicationnel. Paris: Fayard, 1987.

Le discours philosophique de la modernité. Paris: Galimard, 1988.

"L'espace public trente ans après". In: _. L'espace public. Arqueologie de la publicité come dimension constitutive de la société bourgeosie. Paris: Payot, 1993.

Droit et démocratie. Entre faits et normes. Paris: Gallimard, 1996.

HONNETH, A. "Habermas' Theorie der Gesellschaft: Eine kommunikationstheoretische Transformation der Dialektik der Aufklärung". In: Kritik der Macht. Reflexionstufen einer kritischen Gesellschafstheorie. Frankfurt: Suhrkamp, 1986.

"Moralbewußtsein und soziale Klassenherschaft. Einige Schwierigkeiten in der Analyse normativer Handlungspotentiale". In: Die zerrissene Welt des Sozialen. Frankfurt: Suhrkamp, 1990.

; JONAS, H. (orgs.) Communicative action. Essays on Jürgen Habermas's The theory of communicative action. Cambridge: Polity Press, 1991. . Kampf um Anerkennung. Zur moralischen Gramatyk sozialer Konflikte. Frankfurt: Suhrkamp, 1992.

The fragmented world of the social. Essays in social and political philosophy. Albany: State University of New York Press, 1995.

"La dynamique sociale du mépris. D'où parle une théorie critique de la société". In: BOUCHINDOMME, C.; ROCHLITZ, R. (orgs.) Habermas, la raison, la critique. Paris: Cerf, 1996.

. Das Andere der Gerechtigkeit. Aufsätze zur praktischen Philosophie. Frankfurt: Suhrkamp, 2000.

Leiden an Unbestimmtheit. Stuttgart: Reclam, 2001.

"Von Adorno zu Habermas. Zum Gestaltwandel kritischer Gesellschaftstheorie". In: BONB, W.; Kritik. Frankfurt: Suhrkamp.

HORKHEIMER, M.; ADORNO, T. W. La dialetique de la raison. Paris: Gallimard, 1974. HUNYADI, M. La vertu du conflit. Paris: Cerf, 1995.

ISER, M. Kommunikation oder Anerkennung als Paradigma Kritischer Theorie? Über Differenzen der Gesellschaftskritik bei Jürgen Habermas und Axel Honneth. Diplomarbeit, Freie Universität Berlin. 
A ESFERA PÚBLICA E AS LUTAS POR RECONHECIMENTO...

OLIVIER VOIROL

MAHONEY, J. "Honneth's ethical theory of recognition". In: International Studies in Philosophy, 31 (1).

MEAD, G. L'esprit, le soi et la société. Paris: PUF, 1963.

NEGT, O.; KLUGE, A. Öffentlichkeit und Erfahrung. Zur Organisationsanalyse von bürgelicher und proletariatischer Öffentlichkeit. Frankfurt: Suhramp, 1972.

QUÉRÉ, L. "Agir dans l'espace publique". In: PHARO, P.; __. (orgs.) Les formes de l'action. Paris: Ed. De l'EHESS ("Raisons pratiques").

RENAULT, E. Mépris social. Éthique et politique de la reconnaisannce. Bègles: Ed. Du Passant, 2000. 